\title{
Shake-up in store for Britain's biologists
}

- New organization eliming London

THE biological sciences in Britain's universities are underfunded, short of manpower, and teaching and research are "undesirably fragmented", according to a committee set up by the Universities Grants Committee (UGC) to advise on how academic biology could be 'rationalized'. The results of the review have been shrouded in secrecy until now, and there is likely to be heated debate about the conclusions at a meeting this week of the heads of Britain's biology departments.

Similar reviews of chemistry and physics last year concluded that to maintain quality with the limited funds available resources should be concentrated in large departments-those with at least 20 full-time staff. But the biology committee concludes that resources for biology must expand. Professor Richard Southwood of the University of Oxford, who chaired the UGC committee, says biology will be the "leading science of the twenty-first century". He complains that biology has always been underfunded because when interest in the subject increased in the 1970 s, a period of university expansion had ended and there were increasing constraints on growth. An injection of funds is now necessary to compensate for this, he says.

The committee says that the main problem facing biology is the fragmentation of teaching, research and of the funding mechanisms. To eliminate fragmentation in support, the report recommends money for biology be provided from one research council instead of the current four. Most support for biology is now channelled throught the Science and Engineering Council (SERC). But to avoid competition with the expensive demands of the physical sciences and engineering, the responsibility for biology should not be vested in SERC but in a new biological sciences council.

For research and teaching, the report recommends that all biology departments be grouped into a single organization, within which there should be two distinct subgroups. One, termed M, would focus on molecular sciences, including biophysics, biotechnology, physical biochemistry and molecular genetics. The other, called B, would focus on traditional areas of biology such as physiology, ecology, entomology and evolutionary studies. Most biologists do not dispute that more integration of their departments is desirable, but the $\mathrm{M} / \mathrm{B}$

\section{Alaskan oil spill}

Washington

THE oil tanker Exxon Valdez last week struck a reef and spilled some $\mathbf{1 1}$ million gallons of crude oil into Prince William sound off the south coast of Alaska. The spill is being called the worst in North American history. The tanker had just left the port of Valdez, the south terminus of the Trans-Alaska Pipeline and was carrying 53 million gallons of oil. Clean-up crews are trying to contain the spill which threatens severe disruption to the local ecosystem.

J.P.

20 members of staff.

Meeting the requirements of size and covering the defined areas at the same time would require "an enormous amount of restructuring"'in universities, said Professor Christopher Arme of the University of Keele, though he agrees that larger departments than exist at present would be desirable. Others have a different view. Professor David Cove of the University of Leeds argues that small departments can be more efficient than large ones, and a greater amount of personal attention to students is rewarded with a better quality of student.

Southwood stresses that closure of any biology department would be shortsighted. The predicted demographic dip in the 1990 s leading to fewer young people of university age is a misleading indicator of future demand. There is likely to be an acute shortage of suitable personnel for posts in biology in universities and research-council institutes in the future, says the report. It supports the schemes of the UGC and the Royal Society to tackle this problem, but warns against central planning in relation to subject and place of study.

One of the concerns of the committee is that traditional areas of biology are increasingly being neglected, and it believes that there should be an equal number of $\mathrm{M}$ and $\mathrm{B}$ departments. Undergraduates would take a three-year degree course in one department, but should have a basic understanding of the biology studied by the other groups. The committee also warns against central planning in distribution of research funds. It is impossible for committees to identify topics that will lead to significant advances in the future, and best value for money will be obtained by research funds allocated by heads of departments. A spectrum of mechanisms for distributing funds should be pyramidal, with a base of many project grants and relatively few large interdisciplinary research centres. Though the government is now considering separating the allocation of funds for teaching and research in Britain, the committee warns against taking any responsibility for research funds away from the universities.

Christine McGourty

\section{Better health ahead}

Sydney

A National strategy for Aboriginal health, released at the annual meeting of health ministers last week, is the first attempt in ten years to deal with the health problems of that population. Australia's 228,000 Aboriginals suffer from poorer health and a lower life-expectancy than the general population. The World Health Organisation said last year that Aborigines have the worst reported standard of health of any indigenous people. The government's strategy includes plans for upgrading health services, providing more health training and educational programmes, and transferring basic Aboriginal health services from the state governments to the Aboriginal health community. The recommendations, if implemented, are expected to cost $A \$ 417$ million.

T.E.

\section{Hair-raising scheme}

\section{New Delhi} that has heretofore gone to waste. But an Indian and a Japanese company have now formed a partnership to turn what was discarded into profit.

Hair is a potentially profitable source of amino acids. Under the new arrangement, Union Bros of Japan will supply expertise, equipment and part of the finance for a \$10-million processing plant being set up at Pondicherry in south India. The plant will consume 1,200 tonnes of human hair a year, turning it into 80 tonnes of $\mathrm{L}$ cysteine, 24 tonnes of $\mathrm{L}$-tyrosine and $\mathbf{1 , 4 0 0}$ tonnes of dry powder containing as many as 19 amino acids. The products are extensively used in the pharmaceutical, food-processing and cosmetic industries. The company expects to make 25 per cent profit and Japan will purchase the entire output for 8 years. Human hair has become an important raw material for amino acids after whaling restrictions made that source scarce. Apart from barbers' shops, the biggest source of human hair in India is the temples, where Hindus shave their heads as a religious custom. One temple in Tirupati Inandhra Pradesh collects 4,000 tonnes of hair a year. K.S.J.
Human hair is one of India's resources 